Suppl.ementary Material for:

\title{
Experimental Determination of Conformational Isomerization Energy Thresholds in Serotonin
}

Tracy A. LeGreve, Jasper R. Clarkson ${ }^{a}$, and Timothy S. Zwier*

Department of Chemistry, Purdue University, West Lafayette, Indiana 47907-2084

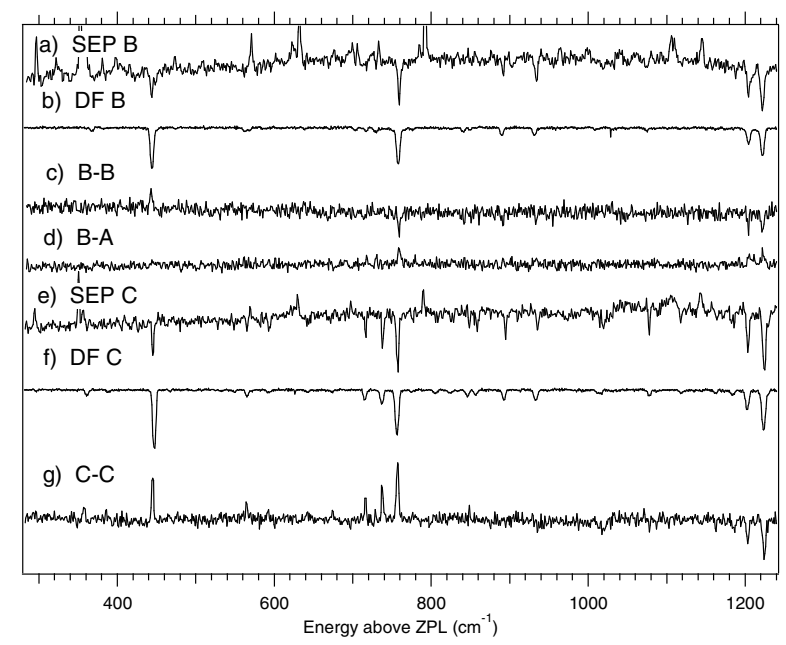

Figure SM1: a) SEP of SERO(B), b) DF of SERO(B), SEP-PT of serotonin c) B $\rightarrow$ B, d) $\mathrm{B} \rightarrow \mathrm{A}, \mathrm{e}) \mathrm{SEP}$ of $\operatorname{SERO}(\mathrm{C}), \mathrm{f})$ DF of $\operatorname{SERO}(\mathrm{C})$, and $\mathrm{g})$ SEP-PT of serotonin $\mathrm{C} \rightarrow \mathrm{C}$.

The SEP and DF spectra of B and C show the major bands of interest for comparison with the SEP-PT spectra. The $\mathrm{B} \rightarrow$ A spectrum shows a clear onset at $759 \mathrm{~cm}^{-1}$, a threshold that is also reflected in the change from gain to depletion in the $\mathrm{B} \rightarrow \mathrm{B}$ reactant channel scan above it. The $\mathrm{C} \rightarrow \mathrm{C}$ SEP-PT spectrum still shows strong gains at the corresponding bands between $700-760 \mathrm{~cm}^{-1}$, consistent with little transfer of population out of the $\operatorname{SERO}(C)$ at these internal energies.

\footnotetext{
${ }^{a}$ Jasper R. Clarkson, Eastman Chemical Company, TN Operations, PO Box 431, Kingsport, TN, 37662. jclarkson@eastman.com
} 